\title{
SARS CoV-2. The New Pandemic: Review of Present Literature
}

\section{K. SRI SANDHYA ${ }^{1 *}$}

\section{Associate Professor, Department of Microbiology, PIMS, Karimnagar}

*Corresponding author:

Dr. K. Sri Sandhya, Associate Professor, Department of Microbiology, Prathima Institute of Medical Sciences, Nagunur, Karimnagar. Telangana 505417 Mobile no: - 9849015377

Email id: sandhyarameshk12@gmail.com

\section{ABSTRACT:}

A novel Corona virus discovered during a pneumonia outbreak in Wuhan city, China has raised a global public health concern. This virus spread across the world affecting various countries and was declared a pandemic by World Health Organization(WHO). The outbreak started in December 2019 and by first week of April 2020, 212 countries were affected with more than 1 million confirmed cases with a death roll of 79,235 worldwide. This disease was named as COVID-19 and the causative agent was named as Severe Acute Respiratory Syndrome Corona Virus -2 (SARS-CoV-2) due to its genetic similarity with SARS virus. SARS-CoV-2 is transmitted by respiratory droplets and by contact. Clinical symptoms include high fever, sore throat, cough, breathlessness, progress to pneumonia, acute respiratory distress and multisystem dysfunction. Infectivity rate is high with SARSCoV2, as a result many countries are affected. Control measures like are quarantine, lockdown, regular handwashing, social distancing have been indicated by WHO and being followed by various countries. Due unavailability of an effective vaccine and specific antiviral medication against the virus, only symptomatic treatment along with the isolation of the patient is being done.

KEYWORDS: COVID-19, SARSCoV-2, pandemic, SARS, quarantine

\section{INTRODUCTION:}

In late December 2019, an unknown viral pneumonia outbreak occurred in Wuhan city, Hubei province, China. ${ }^{(1)}$ the outbreak has spread substantial to infect 9720 people with 213 deaths in China and to infect more than 100 people from other 19 countries till January 2020. ${ }^{(2)}$ The causative agent for this pneumonia outbreak was identified as a novel Corona virus(nCoV) by various laboratories. ${ }^{(3-5)}$ The disease was named as Corona Virus Disease 2019 (COVID-19) by World Health Organization (WHO) and the causative agent was named as Severe Acute Respiratory Syndrome Corona virus- 2 (SARSCOV2).

Till $10^{\text {th }}$ April 2020, According to WHO there were $15,21,252$ confirmed cases with 92,798 deaths from 212 countries worldwide. ${ }^{(6)}$ In India, 6039 cases were confirmed with 206 deaths and 515 cases were cured and discharged from various states. ${ }^{(7)}$ Among all states and Union territories Maharashtra reported highest number of cases with 1364 confirmed cases, 97 deaths and 125 cured cases. Delhi and Tamilnadu reported more than 800 cases each and NorthEastern states Tripura, Mizoram and Arunachal Pradesh has reported one case each. Telangana reported 473 confirmed cases with 35 cured and 7 deaths. ${ }^{(8)}$ (Fig 1)

\section{HISTORY:}

Corona viruses are a diverse group of RNA viruses which cause several diseases involving respiratory, enteric, hepatic and neurological systems in humans and animals with varying severity. ${ }^{(9)}$ There are various corona viruses which cause mild respiratory illness, like HCoV-OC43, HCoV-229E, HCoVNL63 and HCoV-KHU1. ${ }^{(10)}$ Over the past two decades, two novel corona CoVs- severe acute respiratory syndrome corona virus (SARS-CoV) and Middle East respiratory syndrome corona virus (MERS-CoV) have emerged and caused severe human illness in 2003 and 2012 respectively. ${ }^{(11,12)}$ During the epidemic, SARS-CoV, from bat origin and palm civet cats as intermediate host emerged in Guangdong province of China infected more than 8000 people worldwide with 916 deaths (mortality rate 11\%) and MERSCoV, emerged in Saudi Arabia affected 2494 people with 858 deaths (mortality rate $34 \%)^{(13,14)}$

\section{THE VIRUS: MORPGOLOGY AND GENETIC CHARACTERISTICS:}

The new SARSCoV is one among the Corona viruses. Corona viruses belong to genus Corona virus, family Coronaviridae and the Order Nidovirales. ${ }^{(15)}$ Corona viruses are a group of highly diverse, enveloped, single stranded positivesense RNA viruses measuring from $60 \mathrm{~nm}$ to $140 \mathrm{~nm}$ in diameter. They possess spike like projections on their surface giving a crown like appearance, hence the name corona virus. ${ }^{(16)}$

The envelope spike (S) protein mediates receptor binding and membrane fusion and is crucial for determining host tropism and transmission capacity. ${ }^{(17,18,19)} \mathrm{S}$ protein is functionally divided into S1 domain- responsible for receptor binding and S2 domain- responsible for cell membrane 
fusion. ${ }^{(20)}$ SARS-CoV2 uses Angiotensin-Converting Enzyme2 (ACE-2) as an entry receptor in ACE2 expressing cells ${ }^{(4)}$, a character which is similar to SARS-CoV. ${ }^{(21)}$ Biophysical and structural analysis indicated that S prsotein of SARS-CoV- 2 binds ACE- 2 receptors with $10-20$ fold higher affinity than $S$ protein of SARS-CoV ${ }^{(22)}$. This might be the reason for higher infectivity rate of SARS-CoV-2 than SARS CoV.

Genome of Corona viruses is single stranded positivesense RNA. Two-thirds of RNA they have encodes viral polymerase (RdRp), RNA synthesis materials, and two non structutal polyproteins that are not involved in host response modulation (ORF1a-ORF1b). The other one third of the genome encodes four structural proteins - spike (S), envelope (E), membrane (M) and nucleocapsid (N), and other helper proteins. ${ }^{(23)}$ Although the length of $\mathrm{CoV}$ genome shows high variability for ORF1A/ORF1B and four structural proteins, it is mostly associated with the number and size of accessory proteins.

\section{ORIGIN AND SPREAD OF COVID-19}

In December 2019, people in Wuhan city, Hubei province, China started presenting to local hospitals with severe pneumonia of unknown cause. Many of the initial cases had exposure to the Huanan seafood market which also trades live animals. Surveillance system was activated and the samples from the patients were sent to reference labs for diagnosis. On 31st December China notified the outbreak and the Huanan market was closed. On $7^{\text {th }}$ of January the virus was identified as Corona virus that had more than $95 \%$ homology with bat coronavirus and more than $70 \%$ homology with SARSCoV. Environmental samples from the Huanan market also tested positive, signifying that the origin of the virus. ${ }^{(24)}$ The number of cases started increasing exponentially, and also those who do not have exposure to the market were also infected suggesting the fact that human-human transmission is occurring. (25) First death was reported on 11th January 2020. As that was the Chinese new year, massive migration occurred between countries which fuelled the epidemic. Cases from other provinces in China and also from other countries like Thailand, South Korea, Japan were reported in people who are returning from Wuhan. Transmission to healthcare workers who were caring for patients was reported on 20th Jan 2020. By 23rd January, the 11 million population of Wuhan city was placed under lockdown with restrictions of entry and exit. This lockdown was soon extended to other cities in Hubei province. Cases of COVID-19 were reported from various countries who do not have the travel history to China. Airports in different countries including India put in screening mechanisms to detect symptomatic people returning from China and other countries and placed them in isolation and tested them for COVID-19. Soon it was apparent that the infection could be transmitted from asymptomatic carriers and also before the onset of symptoms.
Cases started increasing exponentially and studies reported a doubling time of 1.8. ${ }^{(26)}$ By the end of February 83,652 confirmed cases were reported worldwide among which 78,961 from China with 2791 deaths. ${ }^{(27)}$ First confirmed case from India was reported on 30th January 2020 from Kerala, a student who returned from Wuhan. ${ }^{(28)}$ By the end of February only 3 cases were reported from India, but later there was a sudden spurt in cases. By 9th March, a total of 44 confirmed cases have been reported from India. This includes: Delhi (4), Haryana (14), Jammu (1), Kerala (9), Ladakh (2), Punjab (1), Rajasthan (2), Tamil Nadu (1), Telangana (1), Uttar Pradesh (9).Of these, 16 are foreign nationals. ${ }^{(29)}$ By the end of March more than 900 cases were confirmed with nearly 20 deaths. By 12th April 2020 from India, a total of 8447 cases have been reported in 31 states/union territories with 765 cured, discharged or migrated and 273 deaths. ${ }^{(30)}$ and Globally 16,96 , 588 confirmed ( 85679 new) 10,5952 deaths ( 6262 new) were reported. ${ }^{(31)}$ (fig-2)

\section{PATHOGENESIS AND EPIDEMIOLOGY}

Infection is transmitted through large droplets generated during coughing and sneezing by symptomatic patients but can also occur from asymptomatic people and before onset of symptoms. ${ }^{(32)}$ Studies have shown higher viral loads in the nasal cavity as compared to the throat with no difference in viral burden between symptomatic and asymptomatic people. ${ }^{(33)}$ Patients can be infectious for as long as the symptoms last and even on clinical recovery. Some people may act as super spreaders; a UK citizen who attended a conference in Singapore infected 11 other people while staying in a resort in the French Alps and upon return to the UK. ${ }^{(6)}$ These infected droplets can spread 1-2 $\mathrm{m}$ and deposit on surfaces. The virus can remain viable on surfaces for days in favorable atmospheric conditions but are destroyed in less than a minute by common disinfectants like sodium hypochlorite, hydrogen peroxide etc. ${ }^{(34)}$ Infection is acquired either by inhalation of these droplets or touching surfaces contaminated by them and then touching the nose, mouth and eyes. As per current information, transplacental transmission from pregnant women to their fetus has not been described. However, neonatal disease due to post natal transmission is described. ${ }^{(35)}$ The incubation period varies from 2 to 14 days. Studies have identified angiotensin receptor 2 $\left(A C E_{2}\right)$ as the receptor through which the virus enters the respiratory mucosa. ${ }^{(23)}$

\section{CLINICAL FEATURES:}

The clinical features of COVID-19 are varied, ranging from asymptomatic state to acute respiratory distress syndrome and multi organ dysfunction. The common clinical features include fever (not in all), cough, sore throat, headache, fatigue, headache, myalgia and breathlessness. Thus, they are 
indistinguishable from other respiratory infections. In a subset of patients, by the end of the first week the disease can progress to pneumonia, respiratory failure and death. This progression is associated with extreme rise in inflammatory cytokines including IL2, IL7, IL10, GCSF, IP10, MCP1, MIP1A, and TNFa. ${ }^{(36)}$ The median time from onset of symptoms to dyspnoea was 5 days, hospitalization 7 days and acute respiratory distress syndrome (ARDS) 8 days. The need for intensive care admission was in $25-30 \%$ of affected patients in published series. Complications witnessed included acute lung injury, ARDS, shock and acute kidney injury. Recovery started in the 2 nd or 3rd wk. Adverse outcomes and death are more common in the elderly and those with underlying co-morbidities (50-75\% of fatal cases). Fatality rate in hospitalized adult patients ranged from 4 to $11 \%$. The overall case fatality rate is estimated to range between 2 and $3 \%{ }^{(6)}$

Interestingly, disease in patients outside Hubei province has been reported to be milder than those from Wuhan. ${ }^{(37)}$ Similarly, the severity and case fatality rate in patients outside China has been reported to be milder. This may either be due to selection bias wherein the cases reporting from Wuhan included only the severe cases or due to predisposition of the Asian population to the virus due to higher expression of $\mathrm{ACE}_{2}$ receptors on the respiratory mucosa. ${ }^{(38)}$

Disease in neonates, infants and children has been also reported to be significantly milder than their adult counterparts. In a series of 34 children admitted to a hospital in Shenzhen, China between January 19th and February 7th, there were 14 males and 20 females. The median age was 8 years 11 months and in 28 children the infection was linked to a family member and 26 children had history of travel/ residence to Hubei province in China. All the patients were either asymptomatic (9\%) or had mild disease. No severe or critical cases were seen. The most common symptoms were fever (50\%) and cough (38\%). All patients recovered with symptomatic therapy and there were no deaths. One case of severe pneumonia and multiorgan dysfunction in a child has also been reported.(39) Similarly the neonatal cases that have been reported have been mild.

\section{DIAGNOSIS:}

Patients who satisfy clinical case definition and are epidemiologically linked to a history of travel from affected countries in the last 14 days, or have come in contact with a reverse transcription (RT)-PCR confirmed case or with a patient who is under investigation for SARS-COV-2 within the same period, are considered to be suffering from COVID-19. ${ }^{(40)}$ As the asymptomatic transmission of the virus has been established (32) persons with epidemiological risk exposure should practice strict adherence to standard precautions and control of contact-based transmission.
Preferred clinical samples for establishing the laboratory confirmation of a suspected case include nasopharyngeal and oropharyngeal swabs collected using Dacron swabs, expectorated sputum, BAL fluid, endotracheal aspirate. The clinical sample is to be collected in a sterile container with normal saline which covers the sample; serum samples are collected in pairs in red cap vials (plain vials) with clot activators during both the acute phase and the convalescent phase of the illness. For the transportation of samples to the laboratory, the swabs should be placed in a commercially available viral transport medium. The guidelines recommend triple packaging of the sample. ${ }^{(41)}$ Appropriate details of the patient should be filled in the form.

The receiving facility must be informed beforehand about the case and the transport of the sample. The WHO recommends that the culture of the virus must be done in a BSL-3 laboratory and the RT-PCR be done in a BSL-2 laboratory. ${ }^{(42)}$ While handling specimens of SARS-COV-2, one must ensure that neither the sample nor the HCW is contaminated to minimize any risks and to ensure accuracy of diagnosis. Isolation of SARS-COV-2 can be done in cells lines and the diagnosis has to be confirmed by RT-PCR. Charité Berlin, from Germany, was the first to develop the assay and standardize the protocol for real time RT-PCR. ${ }^{(43)}$ The test detects the presence of three genes- $E, R d R p$ and N. This is done in a step -wise process, with the three genes tested in sequence only if the one before is positive. The seroconversion of the disease is seen by detection of antibodies in convalescent phase serum, after a negative result in acute phase serum sample or a four-fold rise in antibody titres between the acute and convalescent phases. Seroconversion can be confirmed by ELISA or indirect fluorescent antibody test (IFA) ${ }^{(44)}$.

Other laboratory investigations are usually non specific. The white cell count is usually normal or low. There may be lymphopenia; a lymphocyte count $<1000$ has been associated with severe disease. The platelet count is usually normal or mildly low. The CRP and ESR are generally elevated but procalcitonin levels are usually normal. A high procalcitonin level may indicate a bacterial co-infection. The ALT/AST, prothrombin time, creatinine, D-dimer, CPK and LDH may be elevated and high levels are associated with severe disease.

The chest X-ray (CXR) usually shows bilateral infiltrates but may be normal in early disease. The CT is more sensitive and specific. CT imaging generally shows infiltrates, ground glass opacities and sub segmental consolidation. It is also abnormal in asymptomatic patients/ patients with no clinical evidence of lower respiratory tract involvement. In fact, abnormal CT scans have been used to diagnose COVID-19 in suspect cases with negative molecular diagnosis; many of these patients had positive molecular tests on repeat testing ${ }^{(45)}$ 


\section{TREATMENT:}

The first step is to ensure adequate isolation (discussed later) to prevent transmission to other contacts, patients and healthcare worker. Treatment is mostly supportive and symptomatic. Antipyretics in cases of fever, IV fluids to maintain hydration etc. In hypoxic patients, provision of oxygen through nasal prongs, face mask, high flow nasal cannula (HFNC) or non-invasive ventilation is indicated. Mechanical ventilation and even extra corporeal membrane oxygen support may be needed. Antibiotics and antifungals are required if co-infections are suspected or proven. The role of corticosteroids is unproven; While current international consensus and WHO advocate against their use, Chinese guidelines do recommend short term therapy with low-tomoderate dose corticosteroids in COVID-19 ARDS. ${ }^{(46)}$ Detailed guidelines for critical care management for COVID-19 have been published by the WHO. ${ }^{(47)}$ There is, as of now, no approved treatment for COVID-19. Antiviral drugs such as ribavirin, lopinavir-ritonavir have been used based on the experience with SARS and MERS. In a historical control study in patients with SARS, patients treated with lopinavir-ritonavir with ribavirin had better outcomes as compared to those given ribavirin alone. ${ }^{(36)}$

In the case series of 99 hospitalized patients with COVID-19 infection from Wuhan, oxygen was given to $76 \%$, non-invasive ventilation in $13 \%$, mechanical ventilation in $4 \%$, extracorporeal membrane oxygenation (ECMO) in $3 \%$, continuous renal replacement therapy (CRRT) in 9\%, antibiotics in $71 \%$, antifungals in $15 \%$, glucocorticoids in $19 \%$ and intravenous immunoglobulin therapy in $27 \% .{ }^{(36)}$ Antiviral therapy consisting of oseltamivir, ganciclovir and lopinavirritonavir was given to $75 \%$ of the patients. The duration of non-invasive ventilation was 4-22 days and mechanical ventilation for 3-20 days.

\section{PREVENTION OF TRANSMISSION}

SARS-CoV-2 spreads via respiratory droplets and physical contact. It is essential to practice precautionary measures to prevent transmission. Standard precautions consist of hand hygiene, use of personal protective equipment (PPE) and respiratory and cough etiquettes. Hand hygiene should be done with alcohol-based hand rubs (ABHRs) containing 60-80 per cent ethanol. Hand washing following the correct steps with soap and water should suffice. Cloth towels should be avoided for drying hands and disposable tissue papers are preferred. PPE consists of the medical masks or particulate respirators, face shields or goggles, gowns, gloves and shoe covers. $(48,49)$ For droplet and contact-based transmission, medical masks or procedure masks with head straps should suffice. This should be worn before entering the patient area and should be taken off only after leaving the same. It is mandatory for persons in the community settings who are symptomatic, the patients who are in home care setups and suspected cases of COVID-19 with mild respiratory symptoms and healthcare workers (due to their elevated risk of exposure) need to wear medical masks at all times followed by hand hygiene and correct disposal.(49) Particulate respirators (NIOSH-certified N95, EU standard FFP2 or equivalent) should be used by HCWs involved in aerosolgenerating procedures (AGPs). Face shields or goggles are to be used by all HCWs while performing AGPs. Long-sleeved, sterile, waterproof gowns, made of non-absorbable materials are to be worn. When gowns are not available, waterproof aprons should be used. Powder-free, latex gloves should be worn while handling infected patient's material. This should not be considered as a replacement of hand hygiene. Shoe covers should also be used in healthcare settings to prevent contamination of clothes. Respiratory and cough etiquettes should be adhered to: covering the nose and mouth while sneezing and coughing, using disposable tissue paper instead of cotton cloth, and if nothing else is available, using the flexed elbow, followed by appropriate hand hygiene.

Symptomatic patients in the community settings should be discouraged from congregating in public or crowded areas. Information, education and communication messages should encourage self-deferral and self-containment for patients who are symptomatic. For home care, patients should be placed in a well-ventilated room. In healthcare settings, the patient should be placed in a negative pressure room.

\section{QUARANTINE AND LOCK DOWN:}

On January 23, 2020, the Government of the People's Republic of China imposed a lockdown on Wuhan to quarantine and prevent the spread of the disease. This was a drastic public health measure. Similarly, Diamond Princess, a cruise ship docked off Yokohama in Japan, was quarantined for two weeks after a tourist who disembarked at Hong Kong tested

positive for SARS-CoV-266,67. The cruise ship had over 3,700 passengers and crew, of whom 705 were tested positive for SARS-CoV-2, making it the second largest site of outbreak outside China at one point. ${ }^{(50)}$

Considering the advantages of lockdown, which reduces or prevents the spread of the virus Government of India announced a lockdown of 21 days upto April 14th. People were advised not to come out of their homes unless an emergency, and mass gatherings were strictly discouraged..$^{(51)}$ If people are to come out for essentials, a safe distance of at least one meter should be maintained. People are advised to use cloth masks by ICMR. All these measures are combined with frequent handwashing. Persons with travel history from affected countries are advised to be in self-quarantine and immediately consult the authorities in case of any symptoms appear. 


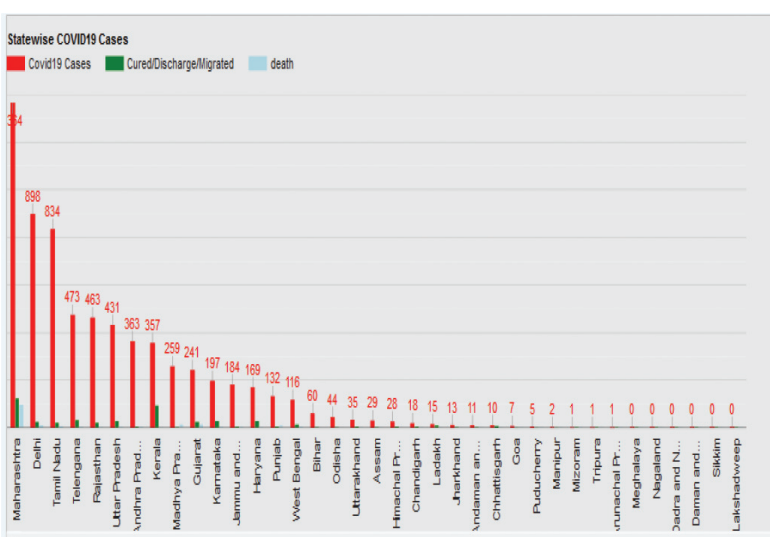

FIGURE 1. Demographic representation of state wide cases till 10th April 2020

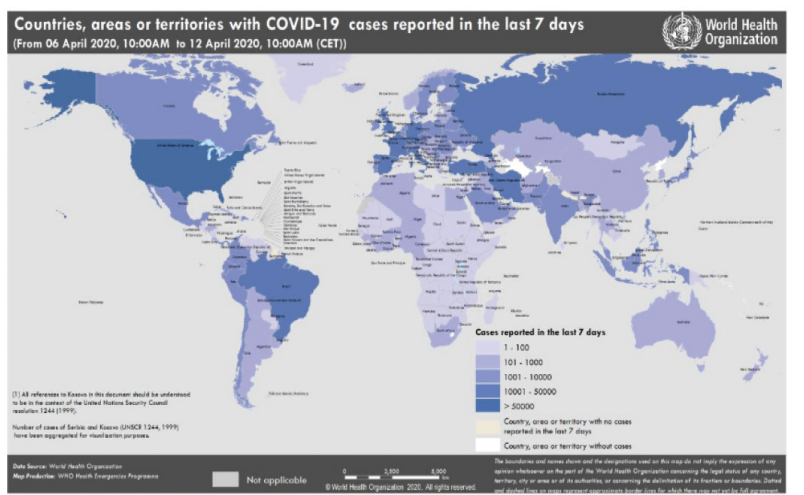

FIGURE 2. Cases reported from various countries by 12 th April 2020

\section{CONCLUSION:}

This review summarizes the current findings of SARSCoV-2 along with the treatment for this severe CoV infection. The most common symptoms were addressed.

The WHO issued a public health emergency of international concern on 30 January 2020. SARS-CoV-2 pandemic became a global concern. At the moment, there is no vaccine and no specific treatment for COVID-19. The best strategy to deal with SARS-CoV-2 epidemic includes controlling the sources of infection, protecting the susceptible people, and cutting off the transmission. The infected patients should be identified early by rapid and robust detection technologies, provided with optimized treatment in isolation timely. The close contact people should be quarantined with follow-up. The healthy people should be aware of the severity of COVID-19 and take measures to protect themselves, such as staying at home, limiting social contacts, and wearing protective mask in public. The authorities should encourage people to stay at home; discourage mass gathering; postpone or cancel public events; and close public institutions. These control measures will help COVID-19 infected countries to prevent the epidemic effectively. Future research will focus on improving the accuracy of early diagnostic tests, developing the vaccine and identifying effective drugs. Therefore, elucidating the pathogenesis of SARS-CoV-2 infection is imperative for achieving such goals.

\section{REFERENCES}

1. Wuhan Municipal Health Commission. Report of Clustering Pneumonia of Unknown etiology in Wuhan city, 2019. http://wjw.wuhan.gov.cn/front/web/showDetail/ 2019123108989.

2. http://www.who.int/docs/default-source/coronavirus/ situation-report/20200131-sitrep-11-ncov.pdf

3. Lu R, Zhao X, Li J, et al. Genomic characterization and epidemiology of 2019 novel corona virus: implications for virus origins and receptor binding. Lancet. 2020;395(10224):565-574

4. Zhou P, yang XL, Wang XG, et al. A pneumonia outbreak associated with a new corona virus of probable bat origin. Nature.2020;579:270-273

5. Zhu N, Zhang D, Wang W, et al. a novel corona virus from patients with pneumonia in China 2019. N Engl J Med. 2020;382(8):727-733

6. https://www.who.int/emergencies/diseases/novelcoronavirus-2019

7. https://www.mygov.in/covid-19/?cbps=1

8. https://www.mohfw.gov.in/

9. He F, Deng Y, Li W. Coronavirus disease 2019: What we know? J Med Virol. 2020;1-7

10. Channappavar R, Zhao J, Perlman S. T-cell mediated immune response to respiratory corona viruses. Immunol Res 2014;59(1-3):118-128

11. Cheng VC, Lau SK, Woo PC, Yuen KY. Severe acute respiratory syndrome coronavirus as an agent of emerging and reemerging infection. Clin Microbiol Rev. 2007;20(4):660-694

12. Chan JF, Lau SK, TO KK, Cheng VC, Woo PC, Yuen KY. Middle East respiratory syndrome coronavirus: another zoonotic betacoronavirus causing SARS-like disease. Clin Microbiol Rev. 2015;28(2);465-522

13. Chan-Yeung $M, X u$ RH. SARS: epidemiology. Respirology. 2003;8:S9-14

14. Middle East Respiratory Syndrome Coronavirus. https:// www.who.int/emergencies/mers-cov/en 
15. Paules $\mathrm{Cl}$, Marston HD, Fauci AS: Coronavirus infectionsmore than just the common cold.

JAMA. 2020, 323:707-708. 10.1001/jama.2020.0757

16. Richman DD, Whitley RJ,Heyden FG. Clinical Virology,4th ed. Washington:ASM Press;2016

17. Wang Q, Wong G, Lu G, Yan J, Gao GF. MERS-CoV spike protein: targets for vaccines and therapeutics. Antiviral Res.2016;133:165-177

18. Lu g, Wang Q, Gao GF. Bat-to-Human: spike features determining 'host jump'of corona viruses SARS-CoV, MERS-CoV, and beyond. Trends microbial. 2015;23(8):468478

19. Li F. Structure, function and evolution of corona virus spike proteins. Annu Rev Virol. 2016;3(1):23237-261

20. He Y, Zhou Y, Liu S, et al. Receptor-binding domain of SARSCoV spike protein induces highly potent neutralizing antibodies; implication for developing subunit vaccine. Biochem Biophys res Commun. 2004;324(2):773-781

21. Li W, Moore MJ, Vasilieva N, et al. Angiotensin-converting enzyme 2 is a functional receptor for the SARS corona virus. Nature. 2003;426(6965);450-454.

22. Wrapp D, Wang N, Corbett KS, et al. Cryo-EM structure of the 2019 nCoV spike in the prefusion confirmation. Science. 2020;367;1260-1263

23. Luk HK, Li X, fung J, Lau SK, Woo PC. Molecular epidemiology, evolution and phylogeny of SARS corona virus. Infection, Genetics and Evolution 2019;71:21-30

24. Xinhua. China's CDC detects a large number of new coronaviruses in the South China seafood market in Wuhan. https:// www.xinhuanet.com/2020-01/27/ c_1125504355.htm

25. Huang C, Wang Y, Li X, et al. Clinical features of patients infected with 2019 novel coronavirus in Wuhan, China. Lancet. 2020;395:497-506

26. Li Q, Guan X, Wu P, et al. Early transmission dynamics in Wuhan, China, of novel coronavirus-infected pneumonia. N Engl J Med.2020. https://doi.org/10.1056/ NEJMoa2001316

27. https://www.who.int/docs/default-source/coronaviruse/ situation-reports/20200228-sitrep-39-covid-19.pdf

28. https://www.who.int/docs/default-source/wrindia/indiasituation-report-1.pdf? sfvrsn $=5$ ca2a672_0
29. https://www.who.int/docs/default-source/wrindia/ situation-report/india-situation-report6606711da860b4d38b266c91265952977.pdf?sfvrsn=2f6c5c95_2

30. https://www.who.int/docs/default-source/wrindia/ situation-report/india-situation-report11.pdf?sfvrsn=438ff245_2

31. https://www.who.int/docs/default-source/coronaviruse/ situation-reports/20200412-sitrep-83-covid19.pdf?sfvrsn=697ce98d_4

32. Rothe C, Schunk M, Sothmann P, Bretzel Gisela, et al Transmission of 2019-nCoV Infection from an Asymptomatic Contact in Germany. N Engl J M. 2020;382(10):970-971.

33. Zou L, Ruan F, Huang M, et al. SARS-CoV-2 viral load in upper respiratory specimens of infected patients. N Engl J Med. 2020. 10.1056/NEJMc2001737.

34. Kampf G, Todt D, Pfaender S, Steinmann E. Persistence of coronaviruses on inanimate surfaces and its inactivation with biocidal agents. J Hosp Infect. 2020 Feb 6. pii: S01956701(20)30046-3.

35. Chen H, Guo J, Wang C, Luo F, et al. Clinical characteristics and intrauterine vertical transmission potential of COVID19 infection in nine pregnant women: a retrospective review of medical records. The Lancet. 2020;395(10226):809-815. doi: 10.1016/S01406736(20)30360-3.

36. Chen N, Zhou M, Dong X, et al. Epidemiological and clinical characteristics of 99 cases of 2019 novel coronavirus pneumonia in Wuhan, China: a descriptive study. Lancet. 2020;395:507-513. doi: 10.1016/S0140-6736(20)302117.

37. $X u X W, W u X X$, Jiang $X G$, et al. Clinical findings in a group of patients infected with the 2019 novel coronavirus (SARS-Cov-2) outside of Wuhan, China: retrospective case series. BMJ. 2020;368:m606. doi: 10.1136/bmj.m606.

38. Cheng ZJ, Shan J. 2019 novel coronavirus: where we are and what we know. Infection. 2020:1-9. 10.1007/s15010020-01401-y

39. Chen F, Liu ZS, Zhang FR, et al. First case of severe childhood novel coronavirus pneumonia in China. Zhonghua Er Ke Za Zhi. 2020;58:E005

40. Center for Health Security. Diagnostic testing for 2019nCoV January 28, 2020. Johns Hopkins Bloomberg School of Public Health; 2020. Available from: http:// 
www.centerforhealthsecurity.org/resources/COVID-19/ 200130-nCoV-diagnostics-factsheet.pdf

41. World Health Organization. Guidelines for the safe transport of infectious substances and diagnostic specimens. Available from: https://www.who.int/csr/ resources/publications/biosafety/whoemc973.pdf

42. World Health Organization. Laboratory testing for 2019 novel coronavirus (2019-nCoV) in suspected human cases. Geneva: WHO; 2020.

43. Corman V, Landt O, Koopmans M, Zambon M, Peiris M. Diagnostic detection of 2019-nCoV by real-time RTPCR:Protocol and primary evaluation. London: Public Health England; 2020.

44. Pang J, Wang MX, Ang IYH, et al. Potential rapid diagnostics, vaccine and therapeutics for 2019 novel coronavirus (2019-nCoV): A systematic review. J sClin Med 2020; 9 : 623

45. Huang Peikai, Liu Tianzhu, Huang Lesheng, Liu Hailong, Lei Ming, Xu Wangdong, Hu Xiaolu, Chen Jun, Liu Bo. Use of Chest CT in Combination with Negative RT-PCR Assay for the 2019 Novel Coronavirus but High Clinical Suspicion. Radiology. 2020;295(1):22-23. doi: 10.1148/ radiol. 2020200330 .

46. Zhao JP, Hu Y, Du RH, et al. Expert consensus on the use of corticosteroid in patients with 2019-nCoV pneumonia. Zhonghua Jie He He Hu Xi Za Zhi. 2020;43:E007.

47. WHO. Clinical management of severe acute respiratory infection when novel coronavirus [nCoV] infection is suspected. Available at: https://www.who.int/ publications-detail/clinical-management-of-severe-acuterespiratory-infection-when-novelcoronavirus-[ncov]infection-is-suspected

48. Chang D, Xu H, Rebaza A, Sharma L, Cruz CSD. Protecting health-care workers from subclinical coronavirus infection. Lancet Respir Med 2020; 8 : PE13.

49. World Health Organization. Advice on the use of masks the community, during home care and in health care settings in the context of the novel coronavirus (2019nCoV) outbreak.

Geneva: WHO; 2020.s

50. Normile D. Coronavirus infections keep mounting after cruise ship fiasco in Japan. Available from: https:// www.sciencemag.org/news/2020/02/coronavirusinfections-keep-mountingafter-cruise-ship-fiasco-japan, accessed on February 28, 2020.
51. www.thelancet.com Published online March 27, 2020 https://doi.org/10.1016/S0140-6736(20)30754-6

How to cite this article : Sri Sandhya K. SARS CoV-2. The New Pandemic: Review of Present Literature. Perspectives in Medical Research 2020; 8(1):4-10

Sources of Support: Nil, Conflict of interest: None declared 